\title{
Effectiveness of Disease-Specific mHealth Apps in Patients With Diabetes Mellitus: Scoping Review
}

Claudia Eberle, MD, Prof Dr; Maxine Löhnert, MSc; Stefanie Stichling, MSc

Medicine with Specialization in Internal Medicine and General Medicine, Hochschule Fulda-University of Applied Sciences, Fulda, Germany

Corresponding Author:

Claudia Eberle, MD, Prof Dr

Medicine with Specialization in Internal Medicine and General Medicine

Hochschule Fulda-University of Applied Sciences

Leipziger Strasse 123

Fulda, 36037

Germany

Phone: 496619649 ext 6328

Fax: 496619640649

Email: claudia.eberle@hs-fulda.de

\section{Abstract}

Background: According to the World Health Organization, the worldwide prevalence of diabetes mellitus (DM) is increasing dramatically and DM comprises a large part of the global burden of disease. At the same time, the ongoing digitalization that is occurring in society today offers novel possibilities to deal with this challenge, such as the creation of mobile health (mHealth) apps. However, while a great variety of DM-specific mHealth apps exist, the evidence in terms of their clinical effectiveness is still limited.

Objective: The objective of this review was to evaluate the clinical effectiveness of mHealth apps in DM management by analyzing health-related outcomes in patients diagnosed with type 1 DM (T1DM), type 2 DM (T2DM), and gestational DM.

Methods: A scoping review was performed. A systematic literature search was conducted in MEDLINE (PubMed), Cochrane Library, EMBASE, CINAHL, and Web of Science Core Collection databases for studies published between January 2008 and October 2020. The studies were categorized by outcomes and type of DM. In addition, we carried out a meta-analysis to determine the impact of DM-specific mHealth apps on the management of glycated hemoglobin $\left(\mathrm{HbA}_{1 \mathrm{c}}\right)$.

Results: In total, 27 studies comprising 2887 patients were included. We analyzed 19 randomized controlled trials, 1 randomized crossover trial, 1 exploratory study, 1 observational study, and 5 pre-post design studies. Overall, there was a clear improvement in $\mathrm{HbA}_{1 \mathrm{c}}$ values in patients diagnosed with T1DM and T2DM. In addition, positive tendencies toward improved self-care and self-efficacy as a result of mHealth app use were found. The meta-analysis revealed an effect size, compared with usual care, of a mean difference of $-0.54 \%$ (95\% CI -0.8 to -0.28 ) for T2DM and $-0.63 \%$ (95\% CI -0.93 to -0.32 ) for T1DM.

Conclusions: DM-specific mHealth apps improved the glycemic control by significantly reducing HbA $\mathrm{H}_{1 \mathrm{c}}$ values in patients with T1DM and T2DM patients. In general, mHealth apps effectively enhanced DM management. However, further research in terms of clinical effectiveness needs to be done in greater detail.

(JMIR Mhealth Uhealth 2021;9(2):e23477) doi: $\underline{10.2196 / 23477}$

\section{KEYWORDS}

diabetes mellitus; mobile apps; mHealth apps; medical apps

\section{Introduction}

In today's world, digitalization is always advancing and increasingly connecting the real with the virtual world [1]. As that happens, our mutual understanding of what is meant by the term digitalization changes. While at the end of the 20th century, digitalization described the conversion of information from analog to digital storage, more extensive definitions are used today [2,3]. For example, a human-centered definition describes digitalization as a process in which people, as well as their living and working worlds, are transferred to a digital level [4]. Digitalization changes the way we interact with our world and vice versa [2]. Consequently, it is not surprising that 
digitalization also influences the daily lives of patients and health care providers.

Looking back to the 1970 s, with the beginning of telematics and telemedicine, the focus was on bridging the distance between patients and health care professionals (HCPs) [2]. However, with the emergence of the internet in the 1990s, new communication channels opened up and the principal use of information and communication technologies became the decisive criterion for digitalization in medicine. The term "electronic health" (eHealth) was created [2,5]. In 2015, the term "digital health" came up in the course of the development and use of new technologies. Digital health includes the use of information and communication technologies to support people in maintaining their health. This is realized by creating opportunities for monitoring, managing, and improving their state of health with the aim of adapting medical care to the needs of the individual [2]. One application of digital health and eHealth is mobile health (mHealth) technologies. mHealth refers to medical and health-promoting methods that are supported by mobile devices such as smartphones and tablets $[2,3,5,6]$. A smartphone itself can be used as a device to support health, for example via social networking features [3,7]. However, since the launch of smartphone app stores in 2008, it was only a matter of time until apps became a medium for mHealth solutions $[3,8,9]$.

Because the mHealth app market is very heterogeneous and growing so rapidly, there is currently no general mandated definition of mHealth app [10,11]. However, according to the World Health Organization (WHO), mHealth apps are software programs for smartphones and other devices that aim to influence people's physical, mental, and social well-being in a positive way [12]. In general, medical apps must be distinguished from mHealth apps $[13,14]$. On a side note, if an mHealth app is classified as a medical app, national and international laws, such as the Medical Device Regulation of the European Union (EU 2017/745), must be taken into account. This means that the app has to go through an approval process that includes, for example, risk analyses [14,15]. Therefore, mHealth apps - medical apps in particular — offer the possibility to improve general health care issues and, more specifically, issues related to type 1 (T1DM) and type 2 (T2DM) diabetes mellitus [3,16-18].

Diabetes mellitus (DM) affects millions of people worldwide and its prevalence is rising $[19,20]$. Affecting approximately 462 million people globally, T2DM makes up a significant part of the global burden [19], but the prevalence of T1DM, gestational DM (GDM), and other forms of DM are rising drastically as well [20-22]. Despite the huge improvements in diabetes technologies, such as glucose monitoring systems and insulin pumps, many people with diabetes do not meet glycemic control targets [23] and would benefit from greater flexibility and more individualized diabetes therapy.

This underlines the urgent need to improve diabetes care in addition to HCP visits, such as by supporting digital diabetes self-management [24,25]. mHealth apps offer novel possibilities, and first steps have been taken in this regard by a small but growing part of the DM community [26-29]. In 2015,
DM-specific mHealth apps had been installed approximately 6.7 million times. Since then, the number of installations has increased dramatically, with approximately 15 million installations in 2018 [29] and 46.3 million installations in 2019 [30], which represented approximately $11 \%$ of patients with DM diagnoses worldwide in 2019 [30]. Of the mHealth apps that were installed, $35.8 \%$ focused on T1DM, $47.6 \%$ on T2DM, and $32.0 \%$ on GDM [29]. DM-specific mHealth apps exist in great variety and include different features [31]. Possible app features include tracking of blood glucose levels or insulin usage; calculation of insulin dosages; monitoring of diet, body weight, or physical activities; or providing education or information [3,29,30,32-38]. However, the available evidence on the effectiveness of DM-specific mHealth apps is limited [39]. Therefore, this paper aims to give an overview of the clinical effectiveness of DM-specific mHealth apps on different health-related outcomes for T1DM, T2DM, and GDM. Clinical effectiveness is defined as a process measured by improvements in the parameters of a morbid condition (eg, lowering blood glucose) and aims to provide optimal care, including evidence-based practice [40]. From a clinical point of view, it is important to know the effect size that results from modifying the communication level by using mHealth apps. In clinical practice, these effects must be added to the therapeutic effects (eg, from insulin). This is also important in order to be able to give evidence-based recommendations.

\section{Methods}

\section{Data Sources and Search Strategy}

In October 2020, we conducted a systematic literature search in MEDLINE via PubMed, Cochrane Library, EMBASE, CINAHL, and Web of Science Core Collection in accordance with the Preferred Reporting Items for Systematic Reviews and Meta-Analysis (PRISMA) strategy [41]. These databases are representative of the entire health-related literature on DM, as they are the five largest databases in this field. The search strategy included the following keywords as Medical Subject Headings or EMBASE Subject Headings terms, as well as title and abstract terms: ("diabetes mellitus") AND ("smartphone" OR "mobile phone" OR "cell phone" OR "iOS" OR "android") AND ("mobile applications" OR "app"). The search strategy in PubMed, for example, was as follows: ("diabetes mellitus"[Mesh]) AND ("Smartphone"[Mesh]) OR ("Cell Phone"[Mesh]) OR ("mobile phone"[Title/Abstract]) OR (ios[Title/Abstract]) OR (android[Title/Abstract]) AND (app[Title/Abstract]) OR ("Mobile Applications"[Mesh]).

In addition, we manually searched reference lists and Google Scholar to identify further papers. The search results were filtered in the databases by year (January 2008 to October 2020) and language (German and English). The studies were screened and selected by two independent reviewers.

\section{Eligibility Criteria}

Since this is a scoping review, we have included several study designs and outcomes to summarize the evidence available on the topic. We included primary research studies (randomized controlled trials, exploratory studies, observational studies, and pre- and posttest design studies) and peer-reviewed studies 
published between January 2008 and October 2020. Because English is the worldwide scientific language and the authors are native German, we have taken German and English literature into account.

Studies reporting on the clinical effectiveness of DM-specific mHealth apps in DM management in patients with T1DM, T2DM, and GDM that specified the features of the apps and their health effects were included.

We looked for reported significant changes $(P<.05)$ in health-related oucomes such as glycemic control (eg, glycated hemoglobin $\left[\mathrm{HbA}_{1 \mathrm{c}}\right]$, and hypo- and hyperglycemia), blood pressure, cholesterol, body weight, self-care, and self-efficacy. Self-care was defined and measured as DM self-management that included items assessing general diet, specific diet, exercise, blood glucose testing, foot care, and smoking using a questionnaire. Self-efficacy is a predisposing factor that be impaired in chronic diseases like DM. Increased self-confidence levels, measured by questionnaires, can set the stage for improved glycemic control [42].

Furthermore, we excluded posters, comments, study protocols, duplicates, and studies focused on DM diagnosis or prevention.

\section{Data Extraction}

We extracted the following information about each study: author, year, study design, intervention and control groups, baseline and follow-up $\mathrm{HbA}_{1 \mathrm{c}}$ values, type of $\mathrm{DM}$, sample size, and main findings related to the outcomes of interest.

\section{Data Synthesis and Analysis}

We synthesized the studies according to outcomes because the clinical perspective focuses on the improvement of individual outcomes through the intervention. In addition, we conducted a meta-analysis to assess the impact of the interventions on the management of $\mathrm{HbA}_{1 \mathrm{c}}$.

$\mathrm{HbA}_{1 \mathrm{c}}$ is the most important and most studied clinical outcome related to technological therapy for DM, including mHealth apps. To determine the change in $\mathrm{HbA}_{1 \mathrm{c}}$, we pooled appropriate studies with intervention groups (using mHealth apps only) and control groups (usual care) and calculated the difference in means, with a $95 \%$ confidence interval. We included studies that reported changes in $\mathrm{HbA}_{1 \mathrm{c}}$ as a percentage from baseline to the end of the study for intervention and control groups.

\section{Results}

\section{Overview}

The database search in October 2020 in the five relevant databases yielded a total of 796 hits. After removing the duplicates, there were 654 citations. Based on the titles and abstracts, we excluded 619 unsuitable papers. The reasons for exclusion can be found in the PRISMA (Preferred Reporting Items for Systematic Reviews and Meta-Analyses) flowchart (Figure 1). Furthermore, we excluded 8 unsuitable studies based on their full texts. After the additional manual research, which identified 2 papers, there was a total of 27 suitable studies to include in this scoping review. In total, we included 27 papers analyzing 1646 patients in the intervention groups and 1241 in the control groups. 
Figure 1. PRISMA (Preferred Reporting Items for Systematic Reviews and Meta-Analyses) flowchart.

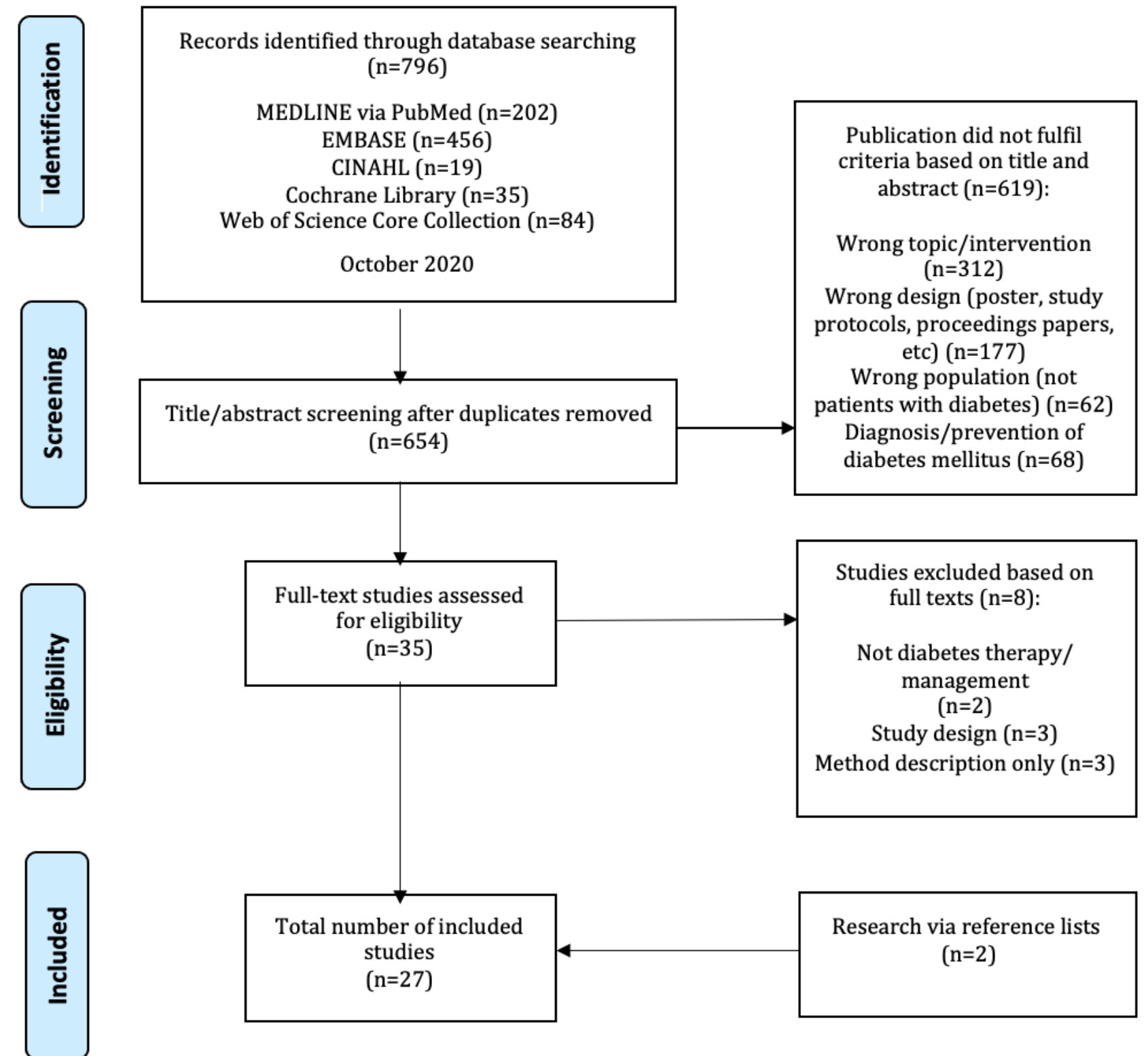

Of the 27 papers, 7 were focused on T1DM (308 patients in the intervention groups and 129 patients in the control groups) [43-49], 12 were focused on T2DM (743 patients in the intervention groups and 645 patients in the control groups) [50-61], and 4 were focused on GDM (339 patients in the intervention groups and 343 patients in the control groups) [62-65]. The remaining 4 papers did not specify the type of DM they looked at or included a mix of DM types ( 256 patients in the intervention groups and 124 patients in the control groups) [66-69]. Multimedia Appendix 1 gives an overview of the included studies. With regard to the study design, we included 19 randomized controlled trials, 1 randomized crossover trial, 1 exploratory study, 1 observational study, and 5 studies that used a pre-post design (1 of which was controlled). Different diabetes mHealth apps were evaluated in each study. As predicted, the apps had a great variability in their features. Some apps included only one feature, such as digital diaries [47,60], feedback on glucose measurements [51], physical activity promotion [53], data transfer to electronic medical records [61], or educational features [52], while other apps combined multiple features. In the following sections, we present the results of the studies sorted by included outcomes.

\section{T1DM Studies}

$\boldsymbol{H b A}_{1 \boldsymbol{c}}$

Overall, 264 patients in the intervention groups and 129 patients in the control groups were investigated in the T1DM studies. In 3 of the 7 studies, significant improvements of $\mathrm{HbA}_{1 \mathrm{c}}$ levels within the intervention groups were found (mean difference: $-1.1 \%, P<.001$ [47]; $-0.3 \%, P<.001$ [45]; and $-0.3 \%, P=.04$ [46]), yielding an $\mathrm{HbA}_{1 \mathrm{c}}$ of $7.73 \%$ on average. Charpentier et al [48] and Drion et al [43] did not report on significance within groups and Rossi et al [49] did not find significant differences $(P=.27)$. Also, 2 studies in which control groups were included reported significant differences between the groups, with better outcomes in the app intervention groups than in the groups receiving usual care $(P<.001$ [47]; $-0.67 \%, P<.001$ [48]). 


\section{Hypo- and Hyperglycemia}

Foltynski et al [44] found a significant $12 \%$ difference in 2-hour postprandial time in range (TIR) in favor of the periods with app support $(P=.031)$. However, they did not find significant differences regarding TIR $(P=.764)$, time $\leq 70 \mathrm{mg} / \mathrm{dL}(P=.764)$, and time $\geq 180 \mathrm{mg} / \mathrm{dL}(P=.883)$ [44]. In addition, Tack et al [46] did not find any significant differences in hypoglycemic events $(P=.21)$.

\section{Fasting Blood Glucose}

Fasting blood glucose was reported in 1 study (41 patients [49]), but a significant change was not found $(P=.09)$.

\section{Self-Care}

Kirwan et al [47] used the Summary of Diabetes Self-Care Activities (SDSCA) questionnaire in their study (36 patients in the intervention group, 36 patients in the control group). On the scales for exercise and blood sugar testing, no significant differences were found $(P>.05)$. On the scale for diet, there were significant differences within groups (3.42 to 4.62 from baseline to end of study in the intervention group, $P<.05$ ) but not between groups (1.2 in intervention group versus -0.05 in control group, $P>.05)$ [47].

\section{Self-Efficacy}

Kirwan et al [47] used the Diabetes Empowerment Scale-Short Form (DES-SF) to examine self-efficacy, but no significant differences between the groups were found.

\section{T2DM Studies}

\section{$H b A_{l c}$}

In total, 743 patients in intervention groups and 645 patients in control groups were investigated in the studies focused on T2DM. Eleven of the studies reported a decrease of $\mathrm{HbA}_{1 \mathrm{c}}$ within the app intervention groups, yielding a mean difference of $-0.42 \%$ [50-52,54-61], but only 1 study reported a significant change of $-1.1 \%(P<.001)$ [56]. The proportion changes when differences between intervention and control groups were considered. Of 11 studies that included control groups in their study design, 7 studies reported significant differences (mean difference: $-0.78 \%,-1.51$ to -0.35 ) in favor of the app intervention groups [51,53-58], while 3 studies did not find a significant difference between groups $[52,59,60]$ and 1 study did not report on differences between groups [61]. Moreover, Kim et al [61] found a significant decrease of $0.4 \%(P<.001)$ in $\mathrm{HbA}_{1 \mathrm{c}}$ in their subgroup analysis for participants with a high satisfaction level and no significant decrease in participants with a low satisfaction level.

\section{Fasting Blood Glucose}

Fasting blood glucose was included in 2 studies (51 patients in the intervention groups and 54 patients in the control groups) [54,57]. Both studies found a significant difference between groups favoring the intervention groups $(-28.23 \mathrm{mg} / \mathrm{dL}, P<.001$ [54]; $-9.6 \mathrm{mg} / \mathrm{dL}, P=.019$ [57]).

\section{Blood Pressure}

None of the 7 studies that reported on blood pressure found significant differences either within or between groups [51-53,55,57,58,61].

\section{Cholesterol}

Cholesterol levels were reported in 7 studies (407 patients in the intervention groups and 348 patients in the control groups). Six studies looked at total cholesterol $[52,53,55,56,58,61]$, but only 1 study found a significant change within the intervention group $(P=.01)$, as well as between the groups $(P=.009)$ [56]. High-density lipoprotein (HDL) cholesterol and low-density lipoprotein (LDL) cholesterol were both included in 7 studies [52,53,55-58,61]. Regarding HDL cholesterol, only 1 study found significant differences within groups $(P=.002$ in the intervention group, $P=.004$ in the control group) and between groups, showing greater improvement and lower values in the control group $(60.67 \mathrm{mg} / \mathrm{dL}$ to $54.33 \mathrm{mg} / \mathrm{dL}$ in the intervention group versus $60.07 \mathrm{mg} / \mathrm{dL}$ to $52.73 \mathrm{mg} / \mathrm{dL}$ in the control group; $P=.048$ ) [56]. With regard to LDL cholesterol, 1 study reported a significant change within the intervention group $(-20.42$ $\mathrm{mg} / \mathrm{dL} ; P=.007)$ and between the intervention and control groups $(P=.01)[56]$.

\section{Body Weight}

Three studies [52,55,59] observed the body weights of 215 patients in intervention groups and 156 patients in control groups. One study reported a significant difference between the groups $(-2.1 \mathrm{~kg}$ in the intervention group versus $0.4 \mathrm{~kg}$ in the control group; $P=.021$ ) [51]. While Holmen et al [59] reported a decrease of body weight in the intervention group, they did not report on the significance. Meanwhile, Kim et al [55] did not report significant differences between the intervention and control groups $(P=.531)$.

\section{Self-Care}

Two studies (229 patients in the intervention groups and 224 patients in the control groups) used the SDSCA questionnaire to evaluate self-care [52,54]. Only 1 study reported a significant difference between the groups $(P<.001)$ [54]. The scales for diet and exercise were also included in 2 studies [52,54], but only one of the studies showed significant differences between the groups for both outcomes $(P<.001)$ [54]. No significant differences were reported for the scales for blood sugar testing $(P=.509)$ [52] or smoking $(P=.729)$ [54], which were each included in one study.

\section{Self-Efficacy}

Chomutare et al [50] (7 patients) reported improvements in scores on the DES-SF and Health Education Impact Questionnaire (heiQ [70]), but they did not report on significance. Kusnanto et al [56] (15 patients in the intervention group and 15 patients in the control group) used a diabetes management self-efficacy scale consisting of 15 questions and found significant improvements within and between the groups (within groups: $15.48, P<.001$ in the intervention group versus 9.6, $P<.001$ in the control group; between groups: $P<.001)$. 


\section{GDM Studies}

$H b A_{l c}$

Two studies [62,64] (167 patients in the intervention groups and 162 in the control groups) investigated the $\mathrm{HbA}_{\mathrm{lc}}$ levels in patients with GDM. One of the studies [62] found a significant difference between the groups in favor of the app intervention $(-1.3 \%$ in the intervention group versus $-0.6 \%$ in the control group; $P<.001$ ), while the other study found no significant difference [64].

\section{Hypo- and Hyperglycemia}

Significant differences between groups favoring the app intervention groups were found for off-target fasting glucose measurements $(P<.001[62,65])$, off-target 1 -hour glucose measurements $(P<.001$ [65]), and off-target 2-hour glucose measurements $(P<.001[62])$.

\section{Blood Glucose and Oral Glucose Tolerance Test}

Miremberg et al [65] reported a significant difference between the intervention and control groups $(P<.001)$, without giving the exact value. Regarding oral glucose tolerance test (OGTT) results, neither Guo et al [62] nor Borgen et al [63] found significant differences in fasting OGTT or 2-hour OGTT.

\section{Self-Care}

Two studies [62,65] (124 patients in the intervention groups and 120 patients in the control groups) included the outcome of patient compliance, defined as the ratio between actual blood glucose measurements and instructed measurements $\times 100$. Both studies found significant differences between the groups, favoring the app intervention groups $(P<.001[62,65])$. In addition, Mackillop et al [64] (103 patients in the intervention group and 102 patients in the control group) reported significant differences in the number of blood glucose readings per day, also favoring the app intervention group $(P<.001)$.

\section{Studies With Type of DM not Specified}

\section{$H b A_{I c}$}

Gunawardena et al [66] reported a significant decrease of $-0.96 \%(P<.001)$ in $\mathrm{HbA}_{1 \mathrm{c}}$ level within the app intervention group and a significant difference $(P<.001)$ between groups in favor of the intervention group. The study by Yu et al [68] did not show a significant difference in $\mathrm{HbA}_{1 \mathrm{c}}$ between the groups $(P>.05)$, but a significant difference was reported regarding the proportion of participants reaching the goal of $\mathrm{HbA}_{1 \mathrm{c}} \leq 7 \%$, with use of the app as the decisive factor $(P<.05)$.

\section{Fasting Plasma Glucose}

Yu et al [68] reported on fasting plasma glucose (48 patients in the app intervention group and 47 patients in the usual care group), but they found no significant differences between the groups $(P>.05)$.

\section{Self-Care}

Kim et al [69] (90 patients in the intervention group) reported significant improvements through the intervention regarding the total SDSCA score $(P<.05)$, as well as on the scales for diet $(0.73, P<.05)$, exercise $(1.11, P<.05)$, blood sugar testing (1.93, $P<.05)$, and smoking $(-0.51, P<.05)$. Jeon and Park [67] (38 patients in the intervention group) used the Information-Motivation-Behavioral skills model as a basis to evaluate their app. They found significant improvements in self-care social motivation $(P=.05)$ and self-care behaviors $(P=.02)$, but they did not find significant differences in self-care information $(P=.85)$, self-care personal motivation $(P=.57)$, or self-care behavioral skills $(P=.89)$ [67].

\section{Effects on $\mathrm{HbA}_{1 \mathrm{c}}$}

Table 1 shows all of the results according to $\mathrm{HbA}_{1 \mathrm{c}}$ values. Effects based on the comparison of $\mathrm{HbA}_{1 \mathrm{c}}$ levels between the intervention and control groups at the study end points were investigated. Findings are presented in Multimedia Appendix 2. The meta-analysis revealed an effect size, compared with usual care, of a mean difference of $-0.54 \%$ (95\% CI -0.8 to -0.28 ) for T2DM (8 suitable studies) and $-0.63 \%$ (95\% CI -0.93 to -0.32 ) for T1DM (2 suitable studies) (Multimedia Appendix 3). 
Table 1. Study results according to glycated hemoglobin $\left(\mathrm{HbA}_{1 \mathrm{c}}\right)$ values.

\begin{tabular}{|c|c|c|c|c|c|}
\hline \multirow[b]{2}{*}{$\begin{array}{l}\text { Diabetes type and } \\
\text { reference }\end{array}$} & \multirow[b]{2}{*}{ Study groups } & \multicolumn{2}{|c|}{$\mathrm{HbA}_{1 \mathrm{c}}(\%)$, mean (SD or $\left.95 \% \mathrm{CI}\right)$} & \multicolumn{2}{|c|}{$\begin{array}{l}\text { Differences in } \mathrm{HbA}_{1 \mathrm{c}}(\%) \text { : mean }(\mathrm{SD} \text { or } 95 \% \\
\mathrm{CI}), P \text { value }\end{array}$} \\
\hline & & Baseline & Follow up & Within groups & Between groups \\
\hline \multicolumn{6}{|l|}{ T2DM $^{\mathbf{a}}$} \\
\hline$[50]$ & Intervention & $6.97(0.69)$ & $6.79(0.68)$ & $\mathrm{NR}^{\mathrm{b}}$ & $\mathrm{N} / \mathrm{A}^{\mathrm{c}}$ \\
\hline$[51]$ & (A) Intervention; (B) control & $\begin{array}{l}\text { (A) } 6.86(1.56) ;(B) \\
7.09(1.51)\end{array}$ & NR & $\begin{array}{l}\text { (A) }-0.40(-0.67 \text { to } \\
-0.14) ;(\mathrm{B}) 0.036 \\
(-0.23 \text { to } 0.30)\end{array}$ & NR, $P=.02$ \\
\hline$[52]$ & (A) Intervention; (B) control & $\begin{array}{l}\text { (A) } 8.1 \text { (1.2); (B) } 8.3 \\
\text { (1.6) }\end{array}$ & $\begin{array}{l}\text { (A) } 8.0 \text { (1.6); (B) } 8.2 \\
\text { (1.4) }\end{array}$ & NR & $\begin{array}{l}-0.08(-0.37 \text { to } 0.2), \\
P=.56\end{array}$ \\
\hline$[53]$ & (A) Intervention; (B) control & $\begin{array}{l}\text { (A) } 6.2(0.6) ;(B) 6.9 \\
(0.7)\end{array}$ & $\begin{array}{l}\text { (A) } 6.2(0.7) ;(B) 7.0 \\
(1.0)\end{array}$ & NR & $\begin{array}{l}-0.9(-1.5 \text { to }-0.2) \\
P=.016\end{array}$ \\
\hline$[54]$ & (A) Intervention; (B) control & $\begin{array}{l}\text { (A) } 7.10(1.22) \text {; (B) } \\
6.85(0.93)\end{array}$ & $\begin{array}{l}\text { (A) } 6.84(0.63) \text {; (B) } \\
8.10(0.10)\end{array}$ & $\begin{array}{l}\text { (A) NR, } P=.232 \text {; (B) } \\
\text { NR, } P<.001\end{array}$ & NR, $P<.001$ \\
\hline$[55]$ & (A) Intervention; (B) control & $\begin{array}{l}\text { (A) } 7.7(0.7) \text {; (B) } 7.8 \\
(0.7)\end{array}$ & NR & $\begin{array}{l}\text { (A) }-0.4(0.09) ;(\mathrm{B}) \\
-0.06(0.1)\end{array}$ & $\begin{array}{l}0.35(0.14 \text { to } 0.55) \\
P<.001\end{array}$ \\
\hline$[56]$ & (A) Intervention; (B) control & $\begin{array}{l}\text { (A) } 8.74(1.34) \text {; (B) } \\
8.18(1.02)\end{array}$ & $\begin{array}{l}\text { (A) } 7.64(1.29) \text {; (B) } \\
7.91(0.88)\end{array}$ & $\begin{array}{l}\text { (A) }-1.1, P<.001 ;(\mathrm{B}) \\
0.27, P=.208\end{array}$ & $\mathrm{NR}, P=.005$ \\
\hline$[57]$ & (A) Intervention; (B) control & $\begin{array}{l}\text { (A) } 7.1(1.0) ;(B) 7.0 \\
(0.9)\end{array}$ & $\begin{array}{l}\text { (A) } 6.7 \text { (0.7); (B) } 7.1 \\
\text { (1.1) }\end{array}$ & (A) -0.4 ; (B) 0.1 & NR, $P=.015$ \\
\hline$[58]$ & $\begin{array}{l}\text { (A) Usual care; (B) app on- } \\
\text { ly; (C) app + web portal; (D) } \\
\text { app + web portal + decision } \\
\text { support }\end{array}$ & $\begin{array}{l}\text { (A) } 9.2(1.7) ;(B) 9.3 \\
(1.8) ;(C) 9.0(1.8) ;(D) \\
9.9(2.1)\end{array}$ & $\begin{array}{l}\text { (A) } 8.5(1.8) ;(\mathrm{B}) 7.7 \\
(1.0) ;(\mathrm{C}) 7.9(1.4) ;(\mathrm{D}) \\
7.9(1.7)\end{array}$ & $\begin{array}{l}\text { (A) }-0.7(-2.3 \text { to } \\
-1.0) ;(\mathrm{B})-1.6(-2.3 \\
\text { to }-1.0) ;(\mathrm{C})-1.2 \\
(-1.8 \text { to }-0.5) ;(\mathrm{D}) \\
-1.9(-2.3 \text { to }-1.5)\end{array}$ & $\begin{array}{l}\text { A vs D: } 1.2(0.5 \text { to } 1.9), \\
P<.001 ; A \text { vs B: NR, } \\
P=.027 ; \text { A vs C: NR, } \\
P=.40\end{array}$ \\
\hline$[59]$ & $\begin{array}{l}\text { (A) Usual care; (B) app; (C) } \\
\text { app }+\mathrm{HCP}^{\mathrm{d}} \text { support }\end{array}$ & $\begin{array}{l}\text { (A) } 8.4 \text { (7.97 to } 8.76) \text {; } \\
\text { (B) } 8.1(7.72 \text { to } 8.53) \text {; } \\
\text { (C) } 8.1 \text { (7.76 to } 8.43)\end{array}$ & $\begin{array}{l}\text { (A) } 8.2(7.77 \text { to } 8.61) \text {; } \\
\text { (B) } 7.8(7.48 \text { to } 8.15) \text {; } \\
\text { (C) } 8.0(7.49 \text { to } 8.41)\end{array}$ & $\begin{array}{l}\text { (A) }-0.16(-0.50 \text { to } \\
0.18) ;(\mathrm{B})-0.31 \\
(-0.67 \text { to } 0.05) ;(\mathrm{C}) \\
-0.15(-0.58 \text { to } 0.29)\end{array}$ & $\begin{array}{l}\text { A vs. B: }-0.22(-0.75 \\
\text { to } 0.32), P=.42 ; \text { A vs } \\
\text { C: } 0.01(-0.52 \text { to } 0.54) \text {, } \\
P=.097\end{array}$ \\
\hline$[60]$ & $\begin{array}{l}\text { (A) Usual care; (B) app; (C) } \\
\text { education program; (D) app } \\
\text { + education program }\end{array}$ & $\begin{array}{l}\text { (A) } 9.2(1.6) ;(B) 9.3 \\
\text { (1.6); (C) } 9.4(1.7) ;(\mathrm{D}) \\
9.2(1.4)\end{array}$ & NR & $\begin{array}{l}\text { (A) }-0.7 \text {; (B) }-0.7 \text {; } \\
\text { (C) }-1.1 \text {; (D) }-1.1\end{array}$ & NR, $P=.771$ \\
\hline$[61]$ & (A) Intervention; (B) control & $\begin{array}{l}\text { (A) } 7.7(0.7) ;(B) 7.7 \\
(0.5)\end{array}$ & $\begin{array}{l}\text { (A) } 7.5(0.7) \text {; (B) } 7.7 \\
(0.7)\end{array}$ & $\begin{array}{l}\text { (A) NR, } P=.077 \text {; (B) } \\
\text { NR, } P=.973\end{array}$ & NR \\
\hline \multicolumn{6}{|l|}{ T1DM $^{\mathrm{e}}$} \\
\hline$[43]^{\mathrm{f}}$ & (A) Intervention; (B) control & $\begin{array}{l}\text { (A) } 61(57 \text { to } 65) \text {; (B) } \\
62(57 \text { to } 66)\end{array}$ & $\begin{array}{l}\text { (A) } 63 \text { (58 to } 67) \text {; (B) } \\
63(57 \text { to } 69)\end{array}$ & $\begin{array}{l}\text { (A) } 1 \text { ( }-1 \text { to } 2) \text {; (B) } 1 \\
\text { (-4 to } 6)\end{array}$ & $-2(-6$ to 5$)$ \\
\hline$[45]$ & Intervention & $8.1(7.5$ to 9.0$)$ & $7.8(6.9$ to 8.3$)$ & NR, $P<.001$ & N/A \\
\hline [46] & Intervention & 7.9 & 7.6 & NR, $P=.04$ & N/A \\
\hline$[47]$ & (A) Intervention; (B) control & $\begin{array}{l}\text { (A) } 9.08(1.18) \text {; (B) } \\
8.47(0.86)\end{array}$ & $\begin{array}{l}\text { (A) } 7.80(0.75) \text {; (B) } \\
8.58(1.16)\end{array}$ & $\begin{array}{l}\text { (A) }-1.10(0.74) \\
P<.001 ;(\mathrm{B}) 0.07 \\
(0.99), \mathrm{NS}^{\mathrm{g}}\end{array}$ & $\mathrm{NR}, P<.001$ \\
\hline$[48]$ & $\begin{array}{l}\text { (A) Usual care; (B) app on- } \\
\text { ly; (C) app + teleconsulta- } \\
\text { tions }\end{array}$ & $\begin{array}{l}\text { (A) } 8.91(0.90) ;(B) \\
9.19(1.14) ;(\mathrm{C}) 9.11 \\
(1.14)\end{array}$ & $\begin{array}{l}\text { (A) } 9.10(1.16) ;(\mathrm{B}) \\
8.63(1.07) ;(\mathrm{C}) 8.41 \\
(1.04)\end{array}$ & NR & $\begin{array}{l}\text { A vs B: } 0.67(0.35 \text { to } \\
0.99), P<.001 ; \text { A vs C: } \\
0.91(0.60 \text { to } 1.21), \\
P<.001 ; \text { B vs C: } P>.05\end{array}$ \\
\hline [49] & Intervention & $7.6(7.3$ to 7.9$)$ & NR & $\begin{array}{l}-0.33(-0.77 \text { to } 0.11), \\
P=.27\end{array}$ & N/A \\
\hline
\end{tabular}

\section{GDM $^{\text {h }}$}




\begin{tabular}{|c|c|c|c|c|c|}
\hline \multirow[b]{2}{*}{$\begin{array}{l}\text { Diabetes type and } \\
\text { reference }\end{array}$} & \multirow[b]{2}{*}{ Study groups } & \multicolumn{2}{|c|}{$\mathrm{HbA}_{1 \mathrm{c}}(\%)$, mean $(\mathrm{SD}$ or $95 \% \mathrm{CI})$} & \multicolumn{2}{|c|}{$\begin{array}{l}\text { Differences in } \mathrm{HbA}_{1 \mathrm{c}}(\%) \text { : mean (SD or } 95 \% \\
\mathrm{CI}), P \text { value }\end{array}$} \\
\hline & & Baseline & Follow up & Within groups & Between groups \\
\hline$[64]$ & (A) Intervention; (B) control & $\begin{array}{l}\text { (A) } 5.42(0.34) \text {; (B) } \\
5.39(0.35)\end{array}$ & NR & $\begin{array}{l}\text { (A) } 0.02 / \text { day; (B) } \\
0.03 / \text { day }\end{array}$ & $\begin{array}{l}-0.01(-0.05 \text { to } 0.03) \text {, } \\
\text { NS }\end{array}$ \\
\hline
\end{tabular}

${ }^{\mathrm{a}}$ T2DM: type 2 diabetes mellitus.

${ }^{\mathrm{b}} \mathrm{NR}$ : not reported.

${ }^{\mathrm{c}} \mathrm{N} / \mathrm{A}$ : not applicable.

${ }^{\mathrm{d}} \mathrm{HCP}$ : health care professional.

'T1DM: type 1 diabetes mellitus.

${ }^{\mathrm{f}} \mathrm{HbA}_{1 \mathrm{c}}$ values in this study were reported in $\mathrm{mmol} / \mathrm{mol}$.

${ }^{\mathrm{g}} \mathrm{NS}$ : not significant.

${ }^{\mathrm{h}} \mathrm{GDM}$ : gestational diabetes mellitus.

\section{Discussion}

\section{Principal Results and Comparison With Prior Work}

In general, specific mHealth apps clearly improved glycemic control by effectively reducing $\mathrm{HbA}_{1 \mathrm{c}}$ values in patients with T1DM (mean difference: $-0.63 \%, 95 \%$ CI $-0.93 \%$ to $-0.32 \%$ ) and T2DM (mean difference: $-0.54 \%, 95 \% \mathrm{CI}-0.8 \%$ to $-0.28 \%)$. While no significant improvements in blood pressure or cholesterol were found in patients with T2DM, a few studies showed positive tendencies toward improved self-care and self-efficacy with regard to patients with DM in general.

The studies were diverse with respect to the type of DM, study design, number of participants, and app features. Often, different app features were combined or the app was used in conjunction with web portals, feedback from HCPs, or Bluetooth-enabled devices. Because of that, it was not possible to distinguish a relationship between specific app features and health outcomes.

However, some effects were clearly demonstrated from the use of DM-specific mHealth apps in general. We categorized the outcomes included in the studies into $\mathrm{HbA}_{1 \mathrm{c}}$, hypo- and hyperglycemia, further glycemic control outcomes, blood pressure, cholesterol, body weight, self-care, self-efficacy, and further outcomes.

Nearly all of the studies ( 22 of 27 studies) included $\mathrm{HbA}_{1 \mathrm{c}}$ level as an outcome, with a total of 2352 patients analyzed. For patients with T1DM, 3 studies reported significant improvements within the intervention groups, with a mean difference of $-0.57 \%$, yielding $\mathrm{HbA}_{1 \mathrm{c}}$ levels of $7.73 \%$ on average, and 2 studies reported significant differences between groups with a mean difference of -0.73 , favoring the intervention groups. Those results are consistent with other reviews. Sun et al [71] reported on 3 studies that showed a significant improvement in $\mathrm{HbA}_{1 \mathrm{c}}$ levels, ranging from $-0.50 \%$ to $-0.58 \%$, in people diagnosed with T1DM. Hou et al [72] reported a significant improvement of $-0.49 \%$ in $\mathrm{HbA}_{1 \mathrm{c}}$ level but rated the grade of evidence to be low. Moreover, Kitsiou et al [73] investigated the effect of mHealth interventions in general and reported an improvement of $-0.3 \%$ in $\mathrm{HbA}_{1 \mathrm{c}}$ levels in people with T1DM.
For T2DM, one of the included studies found a significant improvement in $\mathrm{HbA}_{1 \mathrm{c}}$ levels, approximately $-1.1 \%$, yielding a mean $\mathrm{HbA}_{1 \mathrm{c}}$ of $7.64 \%$ in the intervention group [56], and 7 studies determined a significant difference between intervention and control groups, with a mean difference of $-0.78 \%$, favoring the intervention group. Furthermore, Kim et al [61] showed a significant improvement for users who were highly satisfied with the mHealth app. This could be problematic in light of the results of $\mathrm{Fu}$ et al [74], who found that patients rated the usability of T2DM-specific apps to be "moderate to catastrophic". However, Fu et al [74] also reported similar significant improvements in $\mathrm{HbA}_{1 \mathrm{c}}$ values, based on the results of 4 studies, ranging from $-1.9 \%$ to $-0.4 \%$ [74]. In addition, they highlighted that people with poor glycemic control $\left(\mathrm{HbA}_{1 \mathrm{c}}\right.$ $>9 \%$ ) achieved greater reductions and that apps with interactive features (eg, receiving feedback) were especially likely to show highly significant improvements [74]. The importance of receiving feedback, for example from HCPs, was also reported by Hou et al [72]. In their review, they reported that the higher the frequency of HCP feedback was, the greater was the reduction in $\mathrm{HbA}_{1 \mathrm{c}}$ [72]. All in all, they reported a mean difference of $-0.57 \%$ in $\mathrm{HbA}_{1 \mathrm{c}}$ for patients with $\mathrm{T} 2 \mathrm{DM}$ using mHealth apps [72]. In other reviews, such as one by Cui et al [75], a significant mean difference of $-0.4 \%$ of $\mathrm{HbA}_{1 \mathrm{c}}$ was found between DM-specific mHealth app intervention groups and usual care groups in favor of the intervention groups.

The reported improvements in $\mathrm{HbA}_{1 \mathrm{c}}$ in people with T1DM and T2DM are consistent with the results of the studies that did not specify the type of DM. Of the studies that did not specify the DM type, one study found a significant improvement in $\mathrm{HbA}_{1 \mathrm{c}}$ within the intervention group [66] and the other study found an increase in the proportion of participants with $\mathrm{HbA}_{1 \mathrm{c}}<7 \%$ [68]. No clear effect on $\mathrm{HbA}_{1 \mathrm{c}}$ could be seen in the studies that focused on patients with GDM because of limited data.

The problem of limited data also applies to the study outcomes of hypo- and hyperglycemia and further glycemic control parameters because the studies included different kinds of outcomes. Thus, no clear conclusions can be drawn from them. Other reviews reported an improvement of glycemic control 
through mHealth app interventions $[71,74,75]$ but mainly based their conclusions on $\mathrm{HbA}_{1 \mathrm{c}}$ improvements.

The outcomes of blood pressure, cholesterol, and body weight were only included in studies focusing on T2DM. No effect could be determined for blood pressure, total cholesterol, or HDL or LDL cholesterol because the studies predominantly reported nonsignificant differences. With regard to body weight, no effects could be determined either because of inconclusive study results. This is consistent with the review by Cui et al [75], which did not report on the effects of T2DM-specific mHealth apps on blood pressure, cholesterol, or body weight.

Although the data on the outcomes of self-care and self-efficacy were also limited for all types of DM, the studies showed a trend toward improvements in both. Other studies reported improved DM self-management skills as well [71,76]. However, Hoppe et al [77] criticized the lack of inclusion of behavior change techniques in DM-specific mHealth apps.

Other than the effects on health-related outcomes, different aspects of DM-specific mHealth apps should be taken into account for further research and development. For example, Höchsmann et al [53] highlighted that not just the content of an app is important but also the way it conveys the content. They created their app as a game and found significant effects on $\mathrm{HbA}_{1 \mathrm{c}}$ level and steps per day as a result of the intervention [53]. In addition, Boels et al [52] reminded us that the different needs of people with DM-for example, if someone requires insulin or not-need to be considered. Also, the age of the patients appears to matter. Hou et al [78] showed in their subgroup analyses that young people with T2DM are more likely to benefit from apps. Moreover, elderly people diagnosed with DM may have special needs, such as a larger font size because of reduced eyesight, and not all apps are able to meet these needs [79]. This goes hand in hand with the conclusion of Meister et al [2] that living in the digital world demands a kind of digital literacy. But despite the widespread use of smartphones, digital literacy barriers are common in vulnerable populations, which could reduce the effectiveness of diabetes technologies [80]. Moreover, a lack of standards and regulations lead to potential health risks, for example via misinformation through an mHealth app [39]. Certified medical apps are more trustworthy and should therefore be preferred. However, in the field of DM, they are still rare, and additional online libraries of high-quality DM-specific mHealth apps should be taken into account for recommendations [28]. In addition, data safety in mHealth apps is a serious concern, as they deal with sensitive data $[28,39,81]$. These issues need to be addressed in future studies.

\section{Limitations of the Study}

Although the results of this paper show some possible improvements achieved by using mHealth apps in the treatment of DM, some limitations need to be addressed. A major limitation is the small sample size, especially regarding GDM. Only 4 studies that focused on GDM were included, and they in turn reported predominantly on different outcomes. Thus, no effects of mHealth app use could be determined for patients with GDM. To resolve this issue, we must increase our knowledge of which outcomes are affected by DM-specific mHealth apps and include these outcomes in further studies. In addition, it appears that for patients with GDM, a separate assessment of mHealth app effectiveness is reasonable because outcomes that are important to patients with GDM do not apply in general to patients with T1DM or T2DM, such as different aspects of pregnancy and childbirth. Another limitation of this paper is that the quality of the included studies was not assessed. Therefore, we cannot judge whether an effect was based on poor study quality.

\section{Conclusions}

Overall, this review clearly shows how the use of DM-specific mHealth apps results in improvements in glycemic control by effectively reducing $\mathrm{HbA}_{1 \mathrm{c}}$ levels in patients with T1DM and T2DM. However, a few studies found no significant effects of app use on blood pressure or cholesterol in patients with T2DM. With regard to the other outcomes, only a few suitable studies could be identified. In addition, a handful of studies showed positive tendencies toward improved self-care and self-efficacy as a result of mHealth app use in patients with any type of DM. This suggests a need for further research on the clinical effectiveness of DM-specific mHealth apps.

\section{Acknowledgments}

This research work was supported by the German Research Foundation (Deutsche Forschungsgemeinschaft, DFG), project number EB 440/4-1. Therefore, the authors would like to thank the DFG for the strong support of this research work.

\section{Conflicts of Interest}

None declared.

\section{Multimedia Appendix 1}

Overview of included studies.

[DOCX File, 29 KB-Multimedia Appendix 1]

\section{Multimedia Appendix 2}

Results regarding glycated hemoglobin $\left(\mathrm{HbA}_{1 \mathrm{c}}\right)$ values. 


\section{Multimedia Appendix 3}

Changes in glycated hemoglobin $\left(\mathrm{HbA}_{1 \mathrm{c}}\right)$ values $(\%)$.

[DOCX File, 19 KB-Multimedia Appendix 3]

\section{References}

1. Meister S. Das neue Gesundheits-Ich - souverän, selbstbestimmt und digital unterstützt? GGW 2019;19(3):7-14 [FREE Full text]

2. Meister S, Becker S, Leppert F, Drop L. Digital Health, Mobile Health und Co. - Wertschöpfung durch Digitalisierung und Datenverarbeitung. In: Pfannstiel MA, Da-Cruz P, Mehlich H. editors. Digitale Transformation von Dienstleistungen im Gesundheitswesen I. Wiesbaden: Springer Gabler; 2016:185-212.

3. Eberle C. Einsatz neuer Technologien in Diagnostik und Therapie: Diabetes-Smartphone-Apps. In: Stupin J, Schäfer-Graf U, Hummel M. editors, Praxisorientiertes Wissen zu Gestationsdiabetes, Diabetes mellitus Typ 1 und 2, MODY. Berlin/Boston: Walter de Gruyter; 2020.

4. Hamidian K, Kraijo C. DigITalisierung - Status quo. In: Keuper F. editor. Digitalisierung und Innovation: Planung, Entstehung, Entwicklungsperspektiven. Wiesbaden: Springer Gabler; 2013:1-23.

5. Bundesministerium für Wirtschaft und Energie. Ökonomische Bestandsaufnahme und Potenzialanalyse der digitalen Gesundheitswirtschaft. 2016. URL: https://www.bmwi.de/Redaktion/DE/Publikationen/Studien/ oekonomische-bestandsaufnahme-und-potenzialanalyse-der-digitalen-gesundheitswirtschaft.pdf? blob=publicationFile \&v=6 [accessed 2021-01-28]

6. $\quad$ Eng DS, Lee JM. The promise and peril of mobile health applications for diabetes and endocrinology. Pediatr Diabetes 2013 Jun;14(4):231-238 [FREE Full text] [doi: 10.1111/pedi.12034] [Medline: 23627878]

7. Lee J. Smart health: Concepts and status of ubiquitous health with smartphone. 2011 Sep 01 Presented at: International Conference on ICT Convergence (ICTC); 2011; Seoul p. 388-389. [doi: 10.1109/ictc.2011.6082623]

8. Apple N. Der App Store von Apple feiert 10-jähriges Jubiläum. 2018. URL: https://www.apple.com/de/newsroom/2018/ 07/app-store-turns-10/ [accessed 2021-01-28]

9. Android Developers Blog. Announcing the Android 1.0 SDK, release 1. 2008. URL: https://android-developers. googleblog.com/2008/09/announcing-android-10-sdk-release-1.html [accessed 2021-01-28]

10. Llorens-Vernet P, Miró J. Standards for Mobile Health-Related Apps: Systematic Review and Development of a Guide. JMIR Mhealth Uhealth 2020 Mar 03;8(3):e13057 [FREE Full text] [doi: 10.2196/13057] [Medline: 32130169]

11. Peng W, Kanthawala S, Yuan S, Hussain SA. A qualitative study of user perceptions of mobile health apps. BMC Public Health 2016 Nov 14;16(1):1158 [FREE Full text] [doi: 10.1186/s12889-016-3808-0] [Medline: 27842533]

12. Scherenberg V, Kramer U. Schöne neue Welt: Gesünder mit Health-Apps?: Hintergründe, Handlungsbedarf und schlummernde Potenziale. In: Strahlendorfditor. Jahrbuch Health Care Marketing. Hamburg: New Business; 2013:115-119.

13. U.S. Food and Drug Administration. Device Software Functions Including Mobile Medical Applications. 2019 May 11. URL: https://www.fda.gov/medical-devices/digital-health/device-software-functions-including-mobile-medical-applications [accessed 2021-01-28]

14. Bundesinstitut für Arzneimittel und Medizinprodukte. Orientierungshilfe Medical Apps. URL: https://www.bfarm.de/DE/ Medizinprodukte/Abgrenzung/MedicalApps/ node.html [accessed 2021-01-28]

15. Gießelmann K. Risikoklasse für Apps steigt. Dtsch Arztebl 2018;115(12):A538 [FREE Full text]

16. Taylor S, Pinnock H, Epiphaniou E, Pearce G, Parke H, Schwappach A, et al. A rapid synthesis of the evidence on interventions supporting self-management for people with long-term conditions: PRISMS - Practical systematic Review of Self-Management Support for long-term conditions. NIHR Journals Library 2014 Dec. [doi: 10.3310/hsdr02530]

17. Virella PY, Medlow S, Ho J, Steinbeck K. Mobile and Web-Based Apps That Support Self-Management and Transition in Young People With Chronic Illnessystematic Review. J Med Internet Res 2019;21(11):e13579. [doi: 10.2196/preprints.13579]

18. Shan R, Sarkar S, Martin SS. Digital health technology and mobile devices for the management of diabetes mellitus: state of the art. Diabetologia 2019 Apr 8;62(6):877-887. [doi: 10.1007/s00125-019-4864-7]

19. Khan MAB, Hashim MJ, King JK, Govender RD, Mustafa H, Al Kaabi J. Epidemiology of Type 2 Diabetes - Global Burden of Disease and Forecasted Trends. J Epidemiol Glob Health 2020 Mar;10(1):107-111 [FREE Full text] [doi: 10.2991/jegh.k.191028.001] [Medline: 32175717]

20. Khawandanah J. Double or hybrid diabetes: A systematic review on disease prevalence, characteristics and risk factors. Nutr. Diabetes 2019 Nov 4;9(1):33. [doi: 10.1038/s41387-019-0101-1]

21. McIntyre HD, Catalano P, Zhang C, Desoye G, Mathiesen ER, Damm P. Gestational diabetes mellitus. Nat Rev Dis Primers 2019 Jul 11;5(1):47. [doi: 10.1038/s41572-019-0098-8]

22. You W, Henneberg M. Type 1 diabetes prevalence increasing globally and regionally: the role of natural selection and life expectancy at birth. BMJ Open Diabetes Res Care 2016;4(1):e000161 [FREE Full text] [doi: 10.1136/bmjdrc-2015-000161] [Medline: 26977306] 
23. Carls G, Huynh J, Tuttle E, Yee J, Edelman SV. Achievement of Glycated Hemoglobin Goals in the US Remains Unchanged Through 2014. Diabetes Ther 2017 Aug;8(4):863-873 [FREE Full text] [doi: 10.1007/s13300-017-0280-5] [Medline: 28646411]

24. Azar M, Gabbay R. Web-based management of diabetes through glucose uploads: has the time come for telemedicine? Diabetes Res Clin Pract 2009 Jan;83(1):9-17. [doi: 10.1016/j.diabres.2008.09.055] [Medline: 19056140]

25. Nicoll KG, Ramser KL, Campbell JD, Suda KJ, Lee MD, Wood GC, et al. Sustainability of Improved Glycemic Control After Diabetes Self-Management Education. Diabetes Spectrum 2014 Aug 15;27(3):207-211. [doi: 10.2337/diaspect.27.3.207]

26. Fleming GA, Petrie JR, Bergenstal RM, Holl RW, Peters AL, Heinemann L. Diabetes digital app technology: benefits, challenges, and recommendations. A consensus report by the European Association for the Study of Diabetes (EASD) and the American Diabetes Association (ADA) Diabetes Technology Working Group. Diabetologia 2019 Dec 5;63(2):229-241. [doi: $10.1007 / \mathrm{s} 00125-019-05034-1]$

27. Veazie S, Winchell K, Gilbert J, Paynter R, Ivlev I, Eden KB, et al. Rapid Evidence Review of Mobile Applications for Self-management of Diabetes. J GEN INTERN MED 2018 May 8;33(7):1167-1176. [doi: 10.1007/s11606-018-4410-1]

28. Ahn DT, Stahl R. Is There an App for That? The Pros and Cons of Diabetes Smartphone Apps and How to Integrate Them Into Clinical Practice. Diabetes Spectr 2019 Aug 15;32(3):231-236. [doi: 10.2337/ds18-0101]

29. Eberle C, Ament C. Digitale Diabetologie - Die „Epidemiologie“ diabetes-spezifischer mHealth-Apps im Zeitraum von 2015 bis 2018. Diabetologie und Stoffwechsel 2018;13(S01):S36 [FREE Full text] [doi: 10.1055/s-0038-1641863]

30. Eberle C, Ament C. Digitale Diabetologie - Eine quantitative Analyse diabetesspezifischer mHealth-Apps. Diabetologie und Stoffwechsel 2019;14(S01):S9 [FREE Full text] [doi: 10.1055/s-0039-1688129]

31. Angelini S, Alicastro GM, Dionisi S, Di Muzio M. Structure and Characteristics of Diabetes Self-management Applications: A Systematic Review of the Literature. Comput Inform Nurs 2019 Jul;37(7):340-348. [doi: 10.1097/CIN.0000000000000526] [Medline: 31136332]

32. Eberle C, Ament C. Schwangerschaft und Digitalisierung - Individualisierte Nutzungsanalyse von Schwangerschafts- und GDM-Apps. Diabetologie und Stoffwechsel 2019;14(S01):S56 [FREE Full text] [doi: 10.1055/s-0039-1688270]

33. Eberle C, Ament C. Digitale Diabetologie - Individuelle Nutzungsanalyse diabetes-spezifischer mHealth-Apps. Diabetologie und Stoffwechsel 2018;13(S01):S65 [FREE Full text] [doi: 10.1055/s-0038-1641949]

34. Eberle C, Ament C. Diabetologie und Stoffwechsel 2017;12(S01):S01-S84. [doi: 10.1055/s-0037-1601701]

35. Eberle C, Ament C. Digitale Diabetologie - Update zur individuellen Nutzungsanalyse diabetes-spezifischer mHealth-Apps. Diabetologie und Stoffwechsel 2017;12(S01):S1-S84. [doi: 10.1055/s-0037-1601700]

36. Eberle C, Ament C. Digitale Diabetologie - Spezifische Analyse von Diabetes-Apps hinsichtlich ihrer Funktionen und Nutzerbewertungen. Diabetologie und Stoffwechsel 2016;11(S01):P117. [doi: 10.1055/s-0036-1580864]

37. Eberle C, Ament C. Diabetologie und Stoffwechsel 2015;10(S01):P147. [doi: 10.1055/s-0035-1549513]

38. Eberle C, Ament C. Diabetologie und Stoffwechsel 2015;10(S01):FV7. [doi: 10.1055/s-0035-1549513]

39. Fleming GA, Petrie JR, Bergenstal RM, Holl RW, Peters AL, Heinemann L. Diabetes Digital App Technology: Benefits, Challenges, and Recommendations. A Consensus Report by the European Association for the Study of Diabetes (EASD) and the American Diabetes Association (ADA) Diabetes Technology Working Group. Diabetes Care 2020 Jan;43(1):250-260. [doi: 10.2337/dci19-0062] [Medline: 31806649]

40. "clinical effectiveness". Segen's Medical Dictionary. 2011. URL: https://medical-dictionary.thefreedictionary.com/ clinical+effectiveness [accessed 2021-01-28]

41. Moher D, Liberati A, Tetzlaff J, Altman DG, PRISMA Group. Preferred reporting items for systematic reviews and meta-analyses: the PRISMA statement. Ann Intern Med 2009 Aug 18;151(4):264-9, W64 [FREE Full text] [doi: 10.7326/0003-4819-151-4-200908180-00135] [Medline: 19622511]

42. Dehghan H, Charkazi A, Kouchaki GM, Zadeh BP, Dehghan BA, Matlabi M, et al. General self-efficacy and diabetes management self-efficacy of diabetic patients referred to diabetes clinic of Aq Qala, North of Iran. J Diabetes Metab Disord 2017;16:8 [FREE Full text] [doi: 10.1186/s40200-016-0285-z] [Medline: 28239598]

43. Drion I, Pameijer LR, van DPR, Groenier KH, Kleefstra N, Bilo HJG. The Effects of a Mobile Phone Application on Quality of Life in Patients With Type 1 Diabetes Mellitus: A Randomized Controlled Trial. J Diabetes Sci Technol 2015 May 11;9(5):1086-1091 [FREE Full text] [doi: 10.1177/1932296815585871] [Medline: 25963412]

44. Foltynski P, Ladyzynski P, Pankowska E, Mazurczak K. Efficacy of automatic bolus calculator with automatic speech recognition in patients with type 1 diabetes: A randomized cross-over trial. Journal of Diabetes 2018 Feb 09;10(7):600-608. [doi: 10.1111/1753-0407.12641]

45. Ryan EA, Holland J, Stroulia E, Bazelli B, Babwik SA, Li H, et al. Improved A1C Levels in Type 1 Diabetes with Smartphone App Use. Can J Diabetes 2017 Feb;41(1):33-40. [doi: 10.1016/j.jcjd.2016.06.001] [Medline: 27570203]

46. Tack CJ, Lancee GJ, Heeren B, Engelen LJ, Hendriks S, Zimmerman L, et al. Glucose Control, Disease Burden, and Educational Gaps in People With Type 1 Diabetes: Exploratory Study of an Integrated Mobile Diabetes App. JMIR Diabetes 2018 Nov 23;3(4):e17. [doi: 10.2196/diabetes.9531]

47. Kirwan M, Vandelanotte C, Fenning A, Duncan MJ. Diabetes self-management smartphone application for adults with type 1 diabetes: randomized controlled trial. J Med Internet Res 2013 Nov 13;15(11):e235-e266 [FREE Full text] [doi: 10.2196/jmir.2588] [Medline: 24225149] 
48. Charpentier G, Benhamou P, Dardari D, Clergeot A, Franc S, Schaepelynck-Belicar P, et al. The Diabeo software enabling individualized insulin dose adjustments combined with telemedicine support improves HbA1c in poorly controlled type 1 diabetic patients: a 6-month, randomized, open-label, parallel-group, multicenter trial (TeleDiab 1 Study). Diabetes Care 2011 Mar;34(3):533-539 [FREE Full text] [doi: 10.2337/dc10-1259] [Medline: 21266648]

49. Rossi MCE, Nicolucci A, Pellegrini F, Bruttomesso D, Bartolo PD, Marelli G, et al. Interactive diary for diabetes: A useful and easy-to-use new telemedicine system to support the decision-making process in type 1 diabetes. Diabetes Technol Ther 2009 Jan;11(1):19-24. [doi: 10.1089/dia.2008.0020] [Medline: 19132851]

50. Chomutare T, Tatara N, Årsand E, Hartvigsen G. Designing a diabetes mobile application with social network support. Stud Health Technol Inform 2013;188:58-64. [Medline: 23823289]

51. Orsama A, Lähteenmäki J, Harno K, Kulju M, Wintergerst E, Schachner H, et al. Active assistance technology reduces glycosylated hemoglobin and weight in individuals with type 2 diabetes: results of a theory-based randomized trial. Diabetes Technol Ther 2013 Aug;15(8):662-669. [doi: 10.1089/dia.2013.0056] [Medline: 23844570]

52. Boels AM, Vos RC, Dijkhorst-Oei L, Rutten GEHM. Effectiveness of diabetes self-management education and support via a smartphone application in insulin-treated patients with type 2 diabetes: results of a randomized controlled trial (TRIGGER study). BMJ Open Diab Res Care 2019 Dec 30;7(1):e000981. [doi: 10.1136/bmjdrc-2019-000981]

53. Höchsmann C, Müller O, Ambühl M, Klenk C, Königstein K, Infanger D, et al. Novel Smartphone Game Improves Physical Activity Behavior in Type 2 Diabetes. American Journal of Preventive Medicine 2019 Jul;57(1):41-50. [doi:

10.1016/j.amepre.2019.02.017]

54. Hooshmandja M, Mohammadi A, Esteghamti A, Aliabadi K, Nili M. Effect of mobile learning (application) on self-care behaviors and blood glucose of type 2 diabetic patients. J Diabetes Metab Disord 2019 Jul 12;18(2):307-313. [doi: 10.1007/s40200-019-00414-1]

55. Kim EK, Kwak SH, Jung HS, Koo BK, Moon MK, Lim S, et al. The Effect of a Smartphone-Based, Patient-Centered Diabetes Care System in Patients With Type 2 Diabetes: A Randomized, Controlled Trial for 24 Weeks. Dia Care 2018 Oct 30;42(1):3-9. [doi: 10.2337/dc17-2197]

56. Kusnanto, Widyanata KAJ, Suprajitno, Arifin H. DM-calendar app as a diabetes self-management education on adult type 2 diabetes mellitus: a randomized controlled trial. J Diabetes Metab Disord 2019 Nov 19;18(2):557-563. [doi: 10.1007/s40200-019-00468-1]

57. Waki K, Fujita H, Uchimura Y, Omae K, Aramaki E, Kato S, et al. DialBetics: A Novel Smartphone-based Self-management Support System for Type 2 Diabetes Patients. J Diabetes Sci Technol 2014 Mar 13;8(2):209-215 [FREE Full text] [doi: 10.1177/1932296814526495] [Medline: 24876569]

58. Quinn CC, Shardell MD, Terrin ML, Barr EA, Ballew SH, Gruber-Baldini AL. Cluster-randomized trial of a mobile phone personalized behavioral intervention for blood glucose control. Diabetes Care 2011 Sep;34(9):1934-1942 [FREE Full text] [doi: 10.2337/dc11-0366] [Medline: 21788632]

59. Holmen H, Torbjørnsen A, Wahl AK, Jenum AK, Småstuen MC, Arsand E, et al. A Mobile Health Intervention for Self-Management and Lifestyle Change for Persons With Type 2 Diabetes, Part 2: One-Year Results From the Norwegian Randomized Controlled Trial RENEWING HEALTH. JMIR Mhealth Uhealth 2014 Dec;2(4):e57 [FREE Full text] [doi: 10.2196/mhealth.3882] [Medline: 25499872]

60. Forjuoh SN, Bolin JN, Huber Jr JC, Vuong AM, Adepoju OE, Helduser JW, et al. Behavioral and technological interventions targeting glycemic control in a racially/ethnically diverse population: a randomized controlled trial. BMC Public Health 2014 Jan 23;14:71. [doi: 10.1186/1471-2458-14-71]

61. Kim H, Choi W, Baek EK, Kim YA, Yang SJ, Choi IY, et al. Efficacy of the smartphone-based glucose management application stratified by user satisfaction. Diabetes Metab J 2014 Jun;38(3):204-210 [FREE Full text] [doi: 10.4093/dmj.2014.38.3.204] [Medline: 25003074]

62. Guo H, Zhang Y, Li P, Zhou P, Chen L, Li S. Evaluating the effects of mobile health intervention on weight management, glycemic control and pregnancy outcomes in patients with gestational diabetes mellitus. J Endocrinol Invest 2019 Jun;42(6):709-714. [doi: 10.1007/s40618-018-0975-0] [Medline: 30406378]

63. Borgen I, Småstuen MC, Jacobsen AF, Garnweidner-Holme LM, Fayyad S, Noll J, et al. Effect of the Pregnant+ smartphone application in women with gestational diabetes mellitus: a randomised controlled trial in Norway. BMJ Open 2019 Nov 11;9(11):e030884. [doi: 10.1136/bmjopen-2019-030884]

64. Mackillop L, Hirst JE, Bartlett KJ, Birks JS, Clifton L, Farmer AJ, et al. Comparing the Efficacy of a Mobile Phone-Based Blood Glucose Management System With Standard Clinic Care in Women With Gestational Diabetes: Randomized Controlled Trial. JMIR Mhealth Uhealth 2018 Mar 20;6(3):e71. [doi: 10.2196/mhealth.9512]

65. Miremberg H, Ben-Ari T, Betzer T, Raphaeli H, Gasnier R, Barda G, et al. The impact of a daily smartphone-based feedback system among women with gestational diabetes on compliance, glycemic control, satisfaction, and pregnancy outcome: a randomized controlled trial. American Journal of Obstetrics and Gynecology 2018 Apr;218(4):453.e1-453.e7. [doi: 10.1016/j.ajog.2018.01.044]

66. Gunawardena KC, Jackson R, Robinett I, Dhaniska L, Jayamanne S, Kalpani S, et al. The Influence of the Smart Glucose Manager Mobile Application on Diabetes Management. J Diabetes Sci Technol 2019;13(1):75-81. [doi:

$10.1177 / 1932296818804522]$ 
67. Jeon E, Park H. Experiences of Patients With a Diabetes Self-Care App Developed Based on the Information-Motivation-Behavioral Skills Model: Before-and-After Study. JMIR Diabetes 2019 Apr 18;4(2):e11590 [FREE Full text] [doi: $10.2196 / 11590]$ [Medline: $\underline{30998218]}$

68. Yu Y, Yan Q, Li H, Li H, Wang L, Wang H, et al. Effects of mobile phone application combined with or without self-monitoring of blood glucose on glycemic control in patients with diabetes: A randomized controlled trial. J Diabetes Investig 2019 Sep;10(5):1365-1371 [FREE Full text] [doi: 10.1111/jdi.13031] [Medline: 30815973]

69. Kim YJ, Rhee SY, Byun JK, Park SY, Hong SM, Chin SO, et al. A Smartphone Application Significantly Improved Diabetes Self-Care Activities with High User Satisfaction. Diabetes Metab J 2015 Jun;39(3):207-217 [FREE Full text] [doi: 10.4093/dmj.2015.39.3.207] [Medline: 26124991]

70. Osborne RH, Elsworth GR, Whitfield K. The Health Education Impact Questionnaire (heiQ): an outcomes and evaluation measure for patient education and self-management interventions for people with chronic conditions. Patient Educ Couns 2007 May;66(2):192-201. [doi: 10.1016/j.pec.2006.12.002] [Medline: 17320338]

71. Sun C, Malcolm JC, Wong B, Shorr R, Doyle M. Improving Glycemic Control in Adults and Children With Type 1 Diabetes With the Use of Smartphone-Based Mobile Applications: A Systematic Review. Canadian Journal of Diabetes 2019 Feb;43(1):51-58.e3. [doi: 10.1016/j.jcjd.2018.03.010]

72. Hou C, Xu Q, Diao S, Hewitt J, Li J, Carter B. Mobile phone applications and self-management of diabetes: A systematic review with meta-analysis, meta-regression of 21 randomized trials and GRADE. Diabetes Obes Metab 2018 Dec;20(8):2009-2013. [doi: 10.1111/dom.13307] [Medline: 29582538]

73. Kitsiou S, Paré G, Jaana M, Gerber B. Effectiveness of mHealth interventions for patients with diabetes: An overview of systematic reviews. PLoS One 2017 Mar;12(3):e0173160 [FREE Full text] [doi: 10.1371/journal.pone.0173160] [Medline: $\underline{28249025]}$

74. Fu H, McMahon SK, Gross CR, Adam TJ, Wyman JF. Usability and clinical efficacy of diabetes mobile applications for adults with type 2 diabetes: A systematic review. Diabetes Research and Clinical Practice 2017 Sep;131:70-81. [doi: 10.1016/j.diabres.2017.06.016]

75. Cui M, Wu X, Mao J, Wang X, Nie M. T2DM Self-Management via Smartphone Applications: A Systematic Review and Meta-Analysis. PLoS One 2016 Nov;11(11):e0166718 [FREE Full text] [doi: 10.1371/journal.pone.0166718] [Medline: 27861583]

76. Husted GR, Weis J, Teilmann G, Castensøe-Seidenfaden P. Exploring the Influence of a Smartphone App (Young with Diabetes) on Young People's Self-Management: Qualitative Study. JMIR Mhealth Uhealth 2018 Feb 28;6(2):e43 [FREE Full text] [doi: 10.2196/mhealth.8876] [Medline: 29490897]

77. Hoppe CD, Cade JE, Carter M. An evaluation of diabetes targeted apps for Android smartphone in relation to behaviour change techniques. J Hum Nutr Diet 2017 Jun;30(3):326-338. [doi: 10.1111/jhn.12424] [Medline: 27747955]

78. Hou C, Carter B, Hewitt J, Francisa T, Mayor S. Do Mobile Phone Applications Improve Glycemic Control (HbA1c) in the Self-management of Diabetes? A Systematic Review, Meta-analysis, and GRADE of 14 Randomized Trials. Diabetes Care 2016 Nov;39(11):2089-2095. [doi: 10.2337/dc16-0346] [Medline: 27926892]

79. Isaković M, Sedlar U, Volk M, Bešter J. Usability Pitfalls of Diabetes mHealth Apps for the Elderly. J Diabetes Res 2016;2016:1604609 [FREE Full text] [doi: 10.1155/2016/1604609] [Medline: 27034957]

80. Nouri SS, Avila-Garcia P, Cemballi AG, Sarkar U, Aguilera A, Lyles CR. Assessing Mobile Phone Digital Literacy and Engagement in User-Centered Design in a Diverse, Safety-Net Population: Mixed Methods Study. JMIR Mhealth Uhealth 2019 Aug 29;7(8):e14250. [doi: 10.2196/14250]

81. Heinemann L, Ickrath M. Digitalisierung: Visionen für eine Diabetologie der Zukunft. Dtsch Arztebl 2017;114(41):27-28. [doi: 10.3238/PersDia.2017.10.13.07]

\section{Abbreviations}

DES-SF: Diabetes Empowerment Scale-Short Form

DM: diabetes mellitus

GDM: gestational diabetes mellitus

HCP: health care professional

HDL: high-density lipoprotein

heiQ: Health Education Impact Questionnaire

LDL: low-density lipoprotein

MD: mean difference

mHealth: mobile health

OGTT: oral glucose tolerance test

PRISMA: Preferred Reporting Items for Systematic Reviews and Meta-Analyses

SDSCA: Summary of Diabetes Self-Care Activities

T1DM: type 1 diabetes mellitus

T2DM: type 2 diabetes mellitus 
TIR: time in range

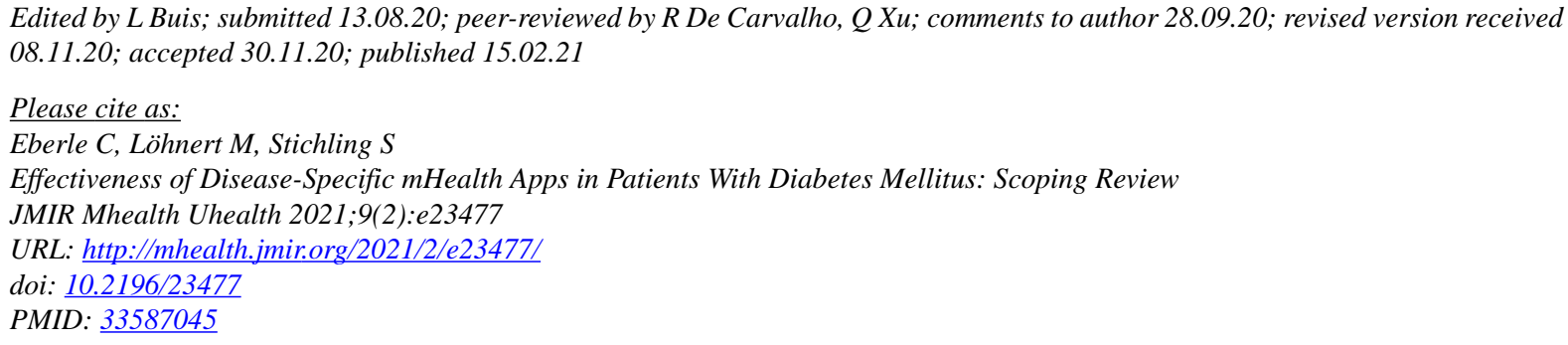

CClaudia Eberle, Maxine Löhnert, Stefanie Stichling. Originally published in JMIR mHealth and uHealth (http://mhealth.jmir.org), 15.02.2021. This is an open-access article distributed under the terms of the Creative Commons Attribution License (https://creativecommons.org/licenses/by/4.0/), which permits unrestricted use, distribution, and reproduction in any medium, provided the original work, first published in JMIR mHealth and uHealth, is properly cited. The complete bibliographic information, a link to the original publication on http://mhealth.jmir.org/, as well as this copyright and license information must be included. 